\title{
Discussion on the English Translation of Characteristic Signs in Northern Region of Shaanxi
}

\author{
Xinzhuo Jiang, Jiaojiao Yang and Shuyao Chen \\ (1.2.3. College of Foreign Languages, Yulin College, Yulin, Shaanxi 719000)
}

\begin{abstract}
In the day of economic globalization, especially in recent years, the characteristics of northern Shaanxi are widely involved in the fields of network, film and television and other works. There are many local characteristics such as dialect, diet and folk culture in northern Shaanxi, which are proud of the national treasures, from generation to generation, those gradually became favorable factors that the northern Shaanxi stands the cultural frontier in the characteristics of China and even the whole world. Therefore, the paper carried out translation studies on dialect, diet, folk culture, mainly by visiting the region and the help of teachers, to develop cultural soft power, improve the international influence of the northern Shaanxi characteristics.
\end{abstract}

Keywords: Northern shaanxi; Distinctive logo; English; Translation

\section{陕北地区特色标志英译探析}

\author{
姜辛卓 $^{1}$, 杨娇娇 ${ }^{2}$, 陈书瑶 ${ }^{3}$
}

\section{(1.2.3. 榆林学院 外国语学院, 陕西榆林 719000)}

摘要: 在经济全球化的今天, 尤其是近年来陕北特色标志广泛涉及网络、影视及文学作品等多方位领域, 陕北地区众多 极具地方特色的标志如方言、饮食、民俗文化等为之骄傲的民族瑰宝, 经过代代相传, 逐渐成为陕北屹立于中国乃至世界民 族特色文化前沿的有利因素。因此文章主要凭借走访考察和师资力量的帮助, 对方言、饮食、民俗文化进行翻译研究, 以发 展文化软实力, 提高陕北特色标志的国际影响力。

关键词: 陕北；特色标志；英语；翻译

\section{引言}

东西方人对于地区特色标志的认知角度、思维方式、审美情趣与价值取向存在差异，尤其是陕北地区 由于缺乏有效的文献资源与可取的英译成果使陕北地区特色标志前进的步伐缓慢许多。因此本文中的英译 研究主要是透过现有的英译表层文化现象来把握深厚文化蕴意, 使特色标志既体现本民族特色和内涵, 也 考虑需求者的文化传统, 尊重文化差异。在这个不断探索发现的过程中提升陕北地区民族文化知名度, 方 便民族特色对外宣传, 扩大民族特色对经济发展的影响，从而使陕北地域文化逐步走向全国，走向世界， 并接受现代化的考验。

\section{1 项目研究内容}

\section{1 方言}

作为语言的变体，方言可根据性质划分为地域方言和社会方言，地域方言是语言因地域方面的差别而 形成的变体, 是语言的不同地域上的分支, 是语言发展不平衡性而在地域上的反映。陕北地处偏僻荒凉的 黄土高原, 几千年来交通阻隔、生产方式稳定保守, 几乎很少受外界影响, 这为方言的保留提供了天然的 文化生态环境。为此我们全面系统地研究陕北方言的具有代表性的语言词汇, 试图揭示陕北方言独特的地 域特征和文化内涵。然而部分陕北方言在英译过程中无法找到对等语, 译者大多采取直译的翻译方法, 这 
样难免会造成原汁原味的地方方言失去了原有的韵味。且看下面的例子：

1.1.1 嗨哈兰: 最普遍的译法只是简单地 “I know”，翻译虽然表达了字面上的意思，但终究少了点 陕北人说此话时的情感色彩与韵味在里面, 因此将其译为 I know it clearly, 搠地有声, 则更贴近陕北人 的豪爽的语气与表达的感情。

1.1 .2 美美嚎了一鼻子: 此处的鼻子既可指普通话中的鼻子，也可指鼻涕。网上的电子翻译为 cried a nose, 则显然不符合正常翻译逻辑, 这里的翻译讲究双关。Choke with sobs , 其中 chock 意为阻塞、使 窒息, 哭泣的时候鼻子处于一种堵塞状态较难说话, 且大多数陕北人前后鼻音不分, 在大哭时尤甚, 与事 实相符。

1.1 .3 不要脸: 不要求眉眼。大多数人在翻译过程中更直白的将其字译为 no face, 于是大家约定俗 成, 包括日常开玩笑中也会如此表达。但看陕北方言中的字面上有眉有眼, 将其更加具象的表达为 shameless from eye and brow. 从眉眼处表现出的 shameless，更符合陕北文化的博大精深。

1.1.4 明明儿街：在没有查证清楚字词在方言中的实际意义便根据表面上的意思开始异想天开的翻 译, 单凭这四个字很容易翻译成为 tomorrow' s street, 闹出笑话, 但只要稍加探索就能够清楚明白的知 道这个词在陕北方言中的意思是: 本来就是。这种胡译乱译现象主要是译者根本不具备翻译的素质, 信手 乱译, 侧面更体现出务实的重要。

\section{2 陕北饮食}

俗话说 “一方水土养一方人”。各地的饮食习惯是由当地生产的粮食作物所决定。由于黄土高原气候 类型表现为半干旱大陆性季风气候, 日照充足, 昼夜温差大, 所以农、林、牧产品丰富多样。陕北地区风 味小吃种类繁多, 经过数千年来劳动人民的传承与创新, 风味小吃营养丰富, 口味独特, 汇聚陕北地区特 色。然而英译过程中出现的种种错误不但会起到误导作用，甚至起一个适得其反的作用。

例如洋芋擦擦。擦擦是一种工具, 用来擦土豆丝的。其以土豆为主要原料, 加些许白面和至而成, 深 得陕北人喜爱。但网络翻译以 Potato wipe 和 Yam wipe 为主, 让局外人会误以为这道小吃非名词而是动 词, 只是擦土豆的一种方式, 词不达意从而使人失去食用的可能。羊杂碎, Haggis 的翻译就显得特别有趣。 这道小吃由羊的肝、心、肥肠、肚、胃、肺等器官烩制而成, 故又名 “羊杂烩”, 其贵在羊杂碎的杂与碎, 不杂不碎, 吃起来就没滋味。羊杂碎集羊内脏于一锅, 虽味道浓厚, 但又清爽不淢, 即 cooked chopped entrails of sheep。这在气候干冷的陕北地区食用可御冷逐寒, 往往半碗才下肚, 便遍体生热。既美味 可口, 又经济实惠。钱钱饭在陕北可谓是家喻户晓, 知名度颇高。它是用压制形似铜钱的黑豆, 和小米同 煮, 或配以其他作物的一种稀饭。黑豆经开水浸泡, 膨圆胀大, 用铁锤捣或放在碾上压成片, 形似铜钱, 所以百姓称之为“钱钱饭”。然而将其英译成为 Money rice 则过于草率与牵强。另外逐字逐词死译或硬译, 但译文根本不符合英语表达习惯。黑愣愣, 本是陕西米脂县、绥德县的一道地方特色小吃, 是将洋芋磨成 粉末状, 经水浸泡过滤后, 加以苂, 面, 佐料, 大葱, 香菜等, 捏成丸状蒸熟, 浇以蒜汁, 陈醋, 香油, 调芝麻原汁原味, 或加青椒西红柿等炒之, 咸辣香爽。然而有关的翻译却采取英语+拼音的手法, 为 Black leng leng 或者 Double black stupid，使人摸不着头脑。

\section{3 陕北民俗文化}

陕北民歌可以称得上是陕北民俗文化的“灵魂”，是陕北民俗风情的一面镜子，它以简单易懂的言辞 
和优美的旋律唱出了陕北劳动人民的心声，人们的喜、怒、哀、乐任何一种情感，都可以通过这种简单的 艺术形式来表达，唱民歌体现了陕北人民朴实的风格特征。

1.3.1 六月里黄河冰不化, 扭着我成亲是我大。

Ice still freezes the Yellow River in June, Marry a man my father forced me to. 《女儿歌》

1.3.2 咱们俩死活哟, 长在一搭。

In the day to make a pair of lovebirds while in the ground to twinned trunks.

《兰花花》

\section{3.3 一对对鹗釒水上漂}

Love birds flow merrily in pairs. 以上的例子对于陕北方言大多采用了意译的手法。例如在 1.3.2, 歌曲本身歌颂的是叛逆女性兰花花坚决反抗封建礼教追求幸福的故事, “长在一搭” 形容其对爱情的美好 向往, 因此运用《长恨歌》的名句 “在天愿做比翼鸟, 在地愿为连理枝” 来形容再合适不过。而中国人惯 用 “鸳春” 来描绘恋人间的亲密无间, 但西方人可能并不了解这一极具特色的汉族文化, 因此在 1.3.3 翻 译的过程中译者特意加上 “in pairs” 来加以说明, 使人豁然开朗。

与陕北民歌具有相似地位的陕北秧歌则是流传于黄土高原的一种极具广泛群众性和代表性的汉族传 统舞蹈, 又称”闹红火”、“闹秧歌”、“闹社火”、“闹阳歌”等。将其音译为“Yangko (a popular rural dance), 既贴近汉语 “种歌” 的发音又在括号里的注释标记清楚其在本地区的地位, 因此在陕北民俗翻译的经典案 例中占有极其重要的地位。

\section{2 结论}

从某种意义上来说, 若想让世界了解陕北, 陕北走向世界, 成功的英译显得尤为重要, 这既是陕北的 名片, 又是外籍人士了解陕北的一面镜子。要做到真正与国际接轨, 唯有采取合适的翻译技巧, 将本地特 色与翻译手法巧妙结合，方能鼓励陕北人民继续发扬当地文化并与其他地区进行跨文化深层次的艺术交流， 提升陕北知名度, 更好的实现陕北地区经济跨越式发展。

\section{参考文献:}

[1] 刘萍. 中式菜有名称的口译 [J]. 中国科技翻译, 2003, 16（8）：18-20.

[2] 熊力游. 中国菜名功能与翻译处理 $[J]$. 长沙大学学报, 2004, 18 (3) : 87-88.

[3] 张俐．论陕北方言在陕北民歌中的作用 $[\mathrm{J}]$ ．西北大学学报．2006，36（5）:84-87.

[4] 张军. 语言学方法与陕北民歌研究 $[J]$. 榆林学院学报, 2006, 4 (5) : 1-4.

[5] 郑茹雪. 刘宏泉. 论中国民歌的翻译 [J]. 商业文化, 2008（10）：153.

[6] 孙国瑾. 严济保. 论中餐菜名英译中的问题与解决办法 [J]. 山东外语教学, 2008，2008（3）：104-108.

[7] 岳秀丽. 古诗词英译中意境美再现的要点及翻译策略 [J] . 甘肃联合大学学报, 2011，27（2）：75-78.

[8] 孟万春. 陕北历史文化研究陕北方言与民俗文化研究 $[J]$. 延安大学学报, 2013，35 (3)：82-85.

[9]秦靖红．陕北方言在陕北民歌中的作用探析 [J]. 价值工程, 2014 (8) : 304-305.

[10］徐佩. 陕北方言中的民歌文化探析 [J]. 延安大学学报, 2016, 38 (1) :125-128.

\section{References:}

[1] Liu Ping. Interpretation of the name of Chinese dishes [J]. Chinese Science and Technology Translation, 2003, 16 (8): 18-20. 
[2] Xiong Liyou. Chinese Name Function and Translation Process [J]. Journal of Changsha University, 2004, 18 (3): 87-88.

[3] Zhang Li. Discussion on the role of northern Shaanxi dialect in northern Shaanxi folk songs [J]. Journal of Northwest University, 2006, 36 (5): 84-87.

[4] Zhang Jun. Study on language method and folk songs in northern Shaanxi [J]. Journal of Yulin University, 2006, 4 (5): 1-4.

[5] Zheng Ruxue. Liu Hongquan. Discussion on the translation of Chinese folk songs [J]. Business culture, 2008 (10): 153.

[6] Sun Guojin. Yan Jibao. Discussion on the problems and solutions of the Chinese food name in the English translation [J]. Shandong Foreign Language Teaching, 2008, 2008 (3): 104-108.

[7] Yue Xiuli. The main points and translation strategiesof ancient poetry in the English translation of the aesthetic beauty [J]. Journal of Gansu Lianhe University, 2011, 27 (2): 75-78.

[8] Meng Wanchun. Northern Shaanxi historical and cultural studies and northern Shaanxi dialect and folk culture research [J]. Journal of Yan'an University, 2013, 35 (3): 82-85.

[9] Qin Jinghong. Research on the role Northern Shaanxi dialect in northern Shaanxi folk songs [J]. Value Engineering, 2014 (8): 304-305.

[10] Xu Pei. Northern Shaanxi dialect in the folk culture [J]. Journal of Yan'an University, 2016, 38 (1): $125-128$. 